\title{
Stab and ballistic performances of aramid fabrics impregnated with silica based shear thickening fluids
}

\author{
Silika esaslı kayma ile kalınlaşan sıvı emdirilmiş aramid kumaşların darbe ve \\ balistik performansları
}

\author{
Oylum Çolpankan Güneş ${ }^{1(D)}$, Sema Yıldız ${ }^{2}(\mathbb{D})$, Mehmet Deniz Güneş ${ }^{3(D)}$, Fikret Şenel ${ }^{4}(\mathbb{D})$, \\ Metin Tanoğlu \\ ${ }^{I}$ Dokuz Eylul University, Metallurgical and Materials Engineering Department, 35390, Izmir Turkey \\ 2,3,5 Izmir Institute of Technology, Mechanical Engineering Department, 35437, Urla-Izmir Turkey \\ ${ }^{4} 5 T P$ LUSAS Defense and Advanced Industry Technologies Inc, 06378 Ankara
}

\begin{abstract}
This study focuses on the production of aramid fabric with improved stab and ballistic resistances treated with shear thickening fluids (STFs). The STFs were prepared by homogenization of various amount of silica particles within the PEG and ethyl alcohol, drying, and grinding steps. The rheological measurements showed that the addition of silica nanoparticles into the PEG, shear thickening behavior was enhanced. As silica concentration increased, the interparticle forces increased and so the friction between particles greatly increased, causing an enhanced shearthickening property. Quasi-static and dynamic stab resistance tests showed that increasing shear thickening response corresponded to increased stab performance in the STF/aramid targets as compared to untreated aramid fabric. Ballistic test results showed that there was an increment in the ballistic resistance between untreated fabric and STF/aramid composites. It was also found that the flexibility of STF/aramid targets did not decrease significantly compared to the untreated aramid fabric.
\end{abstract}

Keywords: Aramid fabric, Shear thickening fluids (STFs), Stab resistance, Rheology, Ballistic performance

\section{Introduction}

Protection of a body from the damages has been always an important issue for mankind. Personal body armors have been designed for this aim to prevent weapons, projectiles, stab threats that come from knives or sharpened equipment such as spike or needle [1-3]. For the body armor production, fabrics made of high-performance fibers which are characterized by low density, high strength, high tenacity and high energy absorption, such as aramid (Kevlar ${ }^{\circledR}$, Aramid $\AA$, Technora $\left.{ }^{\circledR}\right), \quad$ high-density polyethylene (Spectra ${ }^{\circledR}$, Dyneema $\left.{ }^{\circledR}\right)$ and poly benzoxazole $\left(\right.$ Zylon $\left.{ }^{\circledR}\right)$ have been widely used [4-5]. In order to satisfy the protection requirements of body armors, fabrics approximately 20-50 layers are laminated together, or ceramic/steel plates are used along with the fabric structure $[4,6]$. The laminated fabric

\section{Özet}

Bu çalışma, kayma ile kalınlaşan sıvılar (KKSler) ile işlem görmüş gelişmiş bıçak ve balistik dirençlere sahip aramid kumaş üretimine odaklanmaktadır. KKSler, PEG ve etil alkol içinde silika parçacıklarının homojenleştirilmesi, kurutma ve öğütme aşamaları ile hazırlanmıştır. Reolojik ölçümler, silika nanopartiküllerin PEG'e eklenmesinin, kayma ile kalınlaşma davranışını arttığını göstermiştir. Silika konsantrasyonu arttıkça, partiküller arası kuvvetler artmakta ve bu da partiküller arasındaki sürtünmeyi büyük ölçüde arttıarak KKSlerin gelişmiş bir kayma ile kalınlaştırma özelliğine neden olmaktadır. Yarı statik ve dinamik bıçak direnç testleri, artan kayma ile kalınlaşma tepkisinin, KKS/ aramid hedeflerinde ham aramid kumaşa göre artan bıçak performansına karşılık geldiğini göstermiştir. Balistik test sonuçları, ham aramid kumaş ve STF/aramid hedefler arasındaki balistik dirençte artış olduğunu göstermiştir. Ayrıca, STF/aramid hedeflerin esnekliğinin de ham aramid kumaşa göre önemli bir ölçüde azalmadığı da görülmüştür.

Anahtar Kelimeler: Aramid kumaş, Kayma ile kalınlaşan sivilar (KKSler), Darbe direnci, Reoloji, Balistik performans

structured body armor is called as soft body armor and armor with a rigid ceramic or steel plates is known as hard body armor. They differ from each other in protection level; hard body armors are used for the protection against high-speed threats and soft body armors are used for the protection of lower speed threats [5]. Besides having a proper protection level against the threats, weight and flexibility are also important and desired design parameters [7]. However, body armors are bulky, heavy, hard to wear, restrictive the mobility of the wearer due to this laminated structure and heavy plates [6]. Therefore, there is always needed to develop soft body armor materials with flexible, lightweight, higher protection levels against ballistic threats. Recently, STFs has attracted great interest and it has been started to use

\footnotetext{
* Sorumlu yazar / Corresponding author, e-posta / e-mail: metintanoglu @iyte.edu.tr (M. Tanoğlu)

Geliș / Recieved: 01.12.2020 Kabul / Accepted: 14.04.2021 Yayımlanma / Published: 27.07.2021

doi: 10.28948/ngmuh.786231
} 
within the body armors to meet these requirements and the body armor is called as liquid body armor [8].

Shear thickening is a non-Newtonian flow behavior and defined in the British Standard Rheological Nomenclature as the increase in viscosity with increase in shear rate [9]. In general, the shear thickening fluids consist of two phases; nano-scale particles such as silica $[10,11]$, calcium carbonate [12], PMMA particles [13] and medium fluid in which the particles are dispersed in a liquid medium such as polypropylene glycol [14] and polyethylene glycol [15]. Medium fluids act as a lubricant between the nanoparticles. The order-disorder transition and hydrodynamic clustering theories have been the accepted ones in to explain the mechanism of shear thickening fluids [16]. Hoffman et al. proposed that shear thickening is related to an order-disorder transition, the layered structure becomes unstable beyond a critical shear rate [17]. In order to investigate the validity of that mechanism Boersma et al. proposed that short-range lubrication forces are responsible for the formation of shearinduced hydro clusters causing shear thickening [18]. At rest, the void is minimum and there is a random distribution of particles in the fluid. This distribution makes the fluid resistant to flow. However, as increasing shear rates, the liquid lubricates the motion of each particle past others, particles become organized in the direction of the flow which reduces the viscosity; this step is called as shear thinning. At high shear rates, the material expands slightly and hydrodynamic interactions between the particles dominate over stochastic ones. so that there is no longer sufficient liquid to fill the increased void space and the difficulty of particles following around each other in a flow requires the higher energy dissipation and increases the viscosity. This region is a shear thickening region $[19,20]$.

In the literature, Decker et al. proposed a study on the stab resistance of silica based STF-treated fabrics for the first time. The weight percentage of STF was between 20 and 30 . They stated that the stab and puncture resistances of STFtreated Kevlar and nylon fabrics significantly increased compared to the untreated fabrics. They also proposed that the added STF reduced the mobility of filaments and yarns, which led to improvement in stab resistance [21]. In the study of Li et al., silica based STFs were prepared and the chemical composition of dispersing medium as PEG in STF was varied. The results demonstrated that the dynamic stab resistance of ultra-high molecular weight polyethylene (UHMWPE) fabric significantly increased with STF by effectively decreasing the yarn mobility and accelerating the transverse response of UHMWPE fabric. The energy dissipated by STF treated fabrics decreased upon increasing the molecular weight of PEG. In addition, the stab resistance of STF/UHMWPE composites improved with the increase of the concentration and the molecular chain length of additive [22]. Feng et al. studied the effects of fumed silica in shear thickening fluids at a weight fraction of $20 \%$ and submicron silica particles in shear thickening fluids at a weight fraction of $65 \%$ on quasi-static stab resistance properties of fabrics impregnated with shear thickening fluids. They showed that aramid fabrics treated with shear thickening fluid exhibit a significant enhancement in quasi-static stab resistance.
Further, quasi-static stab resistant properties of treated fabrics containing submicron silica particles are better than that of treated fabrics containing fumed silica particles [23]. Kalman et al. studied the role of particle hardness used in STFs. They compared Kevlar fabric treated with STFs consisting silica and PMMA particles in terms of yarn pullout, quasi-static spike puncture, and ballistic penetration resistance. They found that STF treated fabrics resulted in improvement in fabric properties compared to untreated or PEG treated fabrics. On comparison of treatments with different particle hardness, the silica nanoparticles performed better in all tests than comparable PMMA particles [24].

In this study, silica based STF impregnated aramid fabrics were developed and determined the applicability as an armor material. STFs containing dry fumed silica nanoparticles and PEG with a $300 \mathrm{~g} /$ mole molecular weight were prepared after homogenization, drying, and grinding steps. The shear thickening behavior of the STFs at different weight ratios of silica was investigated using a rotational rheometer. The morphological characterization of STFs and STF/aramid fabrics was performed by scanning electron microscopy (SEM). The stab resistance of STF/aramid fabrics were tested based on quasi-static and dynamic stab tests. The ballistic resistance of STF/aramid fabrics were investigated by $9 \mathrm{~mm}$ parabellum projectiles and $\mathrm{V}_{50}$ test performed using 1.1 gr. fragment-simulating projectiles (FSPs). The flexibility of the STF/aramid fabrics were also tested by a new self-made test method.

\section{Material and methods}

\subsection{Materials}

Fumed silica nanoparticles (CAB-O-SIL ${ }^{\circledR}$ M-5, Cabot Corporation, USA.) (200-300 $\mathrm{nm}$ average particle size) were used as a filler in STF synthesis process. Polyethylene glycol (PEG) with a $300 \mathrm{~g} /$ mole molecular weight $\left(\rho=1.12 \mathrm{~g} / \mathrm{cm}^{3}\right.$, $\eta=0.085-0.1 \mathrm{~Pa} . \mathrm{s}$ at $20^{\circ} \mathrm{C}$, melting point $\left.\left(\mathrm{T}_{\mathrm{m}}\right)-15^{\circ} \mathrm{C}\right)$ was used as a medium fluid and supplied by Acros Organics, Belgium. In order to obtain stable dispersions, ethyl alcohol was used, and it was purchased from Tekkim Laboratory Chemicals, Turkey. For the fabrication of soft armor materials, aramid fabrics (TwaronTM) were used. TwaronTM (CT709) is a plain weave of 930f1000 dtex, 2040 yarns with a yarn count of $10^{5} \times 10^{5}$ yarns per $10 \mathrm{~cm}$ and its areal density is $200 \mathrm{~g} / \mathrm{m}^{2}$.

\subsection{Preparation of STFs}

STFs were prepared by dispersing fumed silica nanoparticles in PEG and ethyl alcohol by a sonochemical method, drying and grinding. In this regard, initially, different amount of silica nanoparticles was added to ethyl alcohol at a 1:5 weight ratio of nanoparticle:ethly alcohol and subjected to sonication for 5 hours using Hielscher UP400S ultrasonic processor (Ti-sonotrode with $25 \mathrm{~mm}$ diameter, 50 $\mathrm{Hz}, 28 \mathrm{kWh}$ at $50 \%$ amplitude). Then, PEG was added to the prepared solution and sonication was maintained for 3 hours. Next, the solution was held in an air-circulating oven at $79^{\circ} \mathrm{C}$ overnight in order to evaporate ethyl alcohol in the solution. Finally, it was ground by means of Retsch RM 200 an agate 
mortar $(250 \mathrm{~W}, 100 \mathrm{rpm})$ for 30 minutes and it was placed under vacuum in order to eliminate the bubbles. STFs were coded according to their concentrations in PEG (5-30\% (w/v)) and shown in Table 1.

\subsection{Preparation of STF Impregnated Fabrics}

STF/aramid fabrics were prepared by impregnation of the STFs into the fabric with the soaking method. Initially, the STFs were diluted in ethyl alcohol at a 3:1 volume ratio of ethyl alcohol:STF. Then, ten layers of aramid fabrics having sizes of $20 \times 20 \mathrm{~cm}$ were impregnated with the diluted STFs individually. Finally, after squeezing process to remove excess fluid on the fabrics, they were held in an aircirculating oven at $79^{\circ} \mathrm{C}$. The final concentration of STF in each sample was $15 \%$ by weight. The prepared STF/aramid fabrics were sealed in a $30 \mathrm{~cm}$ laminated polyethylene pouch and sealed. The prepared STF/aramid fabrics were coded according to the impregnated STF as shown in Table 1.

Table 1. Sample codes and concentration

\begin{tabular}{cc}
\hline Sample code & STF concentration $\%(\mathrm{w} / \mathrm{v})$ \\
\hline STF5 & 5 \\
STF10 & 10 \\
STF15 & 15 \\
STF20 & 20 \\
STF25 & 25 \\
STF30 & 30 \\
STF5/aramid & 5 \\
STF10/aramid & 10 \\
STF15/aramid & 15 \\
STF20/aramid & 20 \\
STF25/aramid & 25 \\
STF30/aramid & 30 \\
\hline
\end{tabular}

\subsection{Characterization of the STF Impregnated Fabrics}

\subsubsection{Rheological analysis}

Steady-shear rheological properties of all prepared STFs were investigated by using a rotational rheometer TA instruments TM (TA 2000ex). All the experiments were carried out at room temperature and in a continuous ramp mode using a cone plate having a cone angle of 0.1 radians and a diameter of $25 \mathrm{~mm}$. In this mode, viscosity values were obtained as a function of shear rate and shear rate varied between $10^{-2}$ to $10^{3} \mathrm{~s}^{-1}$ during the experiments.

\subsubsection{Morphological characterization}

In order to determine the dispersibility of silica nanoparticles in the STFs and characterize the impregnation of STF in the aramid fabrics, scanning electron microscope (SEM) (Phillips ${ }^{\text {TM }}$ XL-30S FEG) was utilized at an accelerating voltage of $5 \mathrm{kV}$. All the samples were coated with a thin layer of gold/palladium prior to analysis (Quorum Technologies, SC7620).

\subsubsection{Quasi-static stab resistance tests}

The quasi-static stab test was performed based on NIJ Standard-0115.00 for stab resistance of body armor [25].
Quasi-static stab tests were conducted on treated as well as untreated aramid fabrics by using Schimadzu AGS-J universal test machine with $5 \mathrm{kN}$ load cell. The STF impregnated fabrics and untreated fabrics were placed on a backing material as presented in Figure 1, as specified by the NIJ test standard which consists of four layers of $5.8 \mathrm{~mm}$ thick neoprene sponge, one layer of $31 \mathrm{~mm}$-thick polyethylene foam, two 6.4-mm-thick layers of rubber. The NIJ specified impactor "engineered spike" was used. The spike rate was adjusted to $500 \mathrm{~mm} / \mathrm{min}$ and it was pushed into the target until $30 \mathrm{~mm}$ displacement was achieved. Load as a function of displacement graphs were obtained.

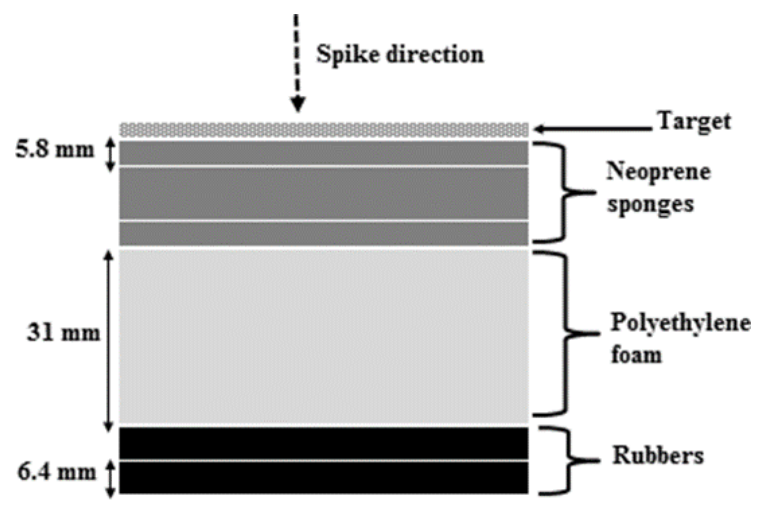

Figure 1. Schematic illustration of quasi-static stab test setup

\subsubsection{Dynamic stab resistance tests}

In order to obtain stab resistances against higher impact velocities dynamic stab tests of STF impregnated aramid fabrics and untreated aramid fabrics were performed by MATEŞ Electronic stab and impact test machine located in BARIŞ Electrical Industry Inc., Ankara, as seen in Figure 2, according to NIJ Standard-0115.00 for stab resistance of body armor. The drop mass contained a cylinder steel and the spike having $9 \mathrm{~mm}$ diameter and the total mass was about $3020 \mathrm{~g}$. The targets were placed on a glass cement having a $55 \mathrm{~mm}$ thickness used as witness paper to measure the depth of indentation. It was placed between the target and foam backing, and behind each layer of neoprene sponge. Test was performed from three different heights $(0.25,0.5$ and 0.75 $\mathrm{m})$. Theoretical impact velocities were calculated as 2.21 , 3.13 and $3.83 \mathrm{~m} / \mathrm{sec}$ based on the heights according to potential and kinetic energy balance equation. Tests were repeated for three times for all samples and the average values were taken.

\subsubsection{Ballistic Tests}

Ballistic tests were conducted using $9 \mathrm{~mm}$ parabellum FMJ projectile and $1.1 \mathrm{~g}$ fragment-simulating projectiles (FSPs) according to 'NIJ-0101. 04 Ballistic Resistance of Personal Body Armor' standard. For $9 \mathrm{~mm}$ parabellum test, exact impact velocity of projectile was measured with a chronograph immediately before impacting the target. The glass cement was used as a backing material and deformation 
of target was measured from this backing material after test was applied. $\mathrm{V}_{50}$ ballistic limit test was applied by using 1.1 g FSPs. After each projectile, the target was controlled, noted that the penetration was full or partial. The test was continued until at least three full and three partial penetrations were observed. $\mathrm{V}_{50}$ result was obtained by the ratio of minimum velocity of full penetration and maximum velocity of partial penetration.

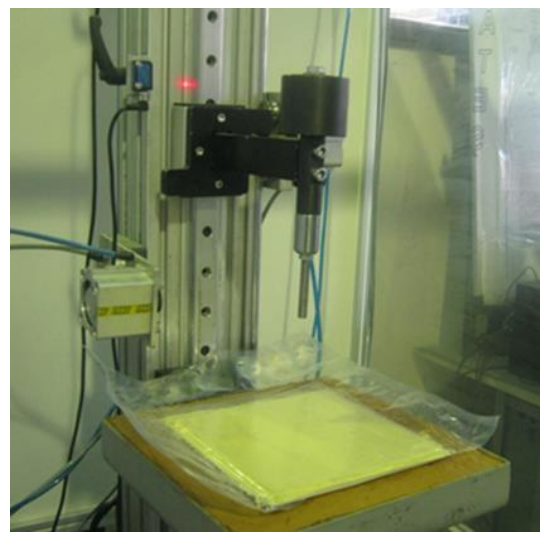

Figure 2. Dynamic stab resistance test setup

\subsubsection{Flexibility Tests}

The flexibility test was performed to determine the effect of STF addition on the fabric flexibility by using Schimadzu AGS-J universal test machine. Schematic test set up for flexibility testing is shown in Figure 3. The test rate was adjusted as $20 \mathrm{~mm} / \mathrm{min}$ and test was maintained until the force of $6 \mathrm{~N}$ was achieved. Bending at the end of the sample is measured, bending angle $(\alpha)$ is calculated by dividing this extension to target edge $(10 \mathrm{~cm})$. Bending angle is reported as a measure of target flexibility, with larger angles indicating greater flexibility. Tests were repeated for three times for all prepared composites and the average values were taken.

\section{Results and discussion}

\subsection{Rheological properties}

Figure 4 shows the steady-shear rheological behavior of PEG 300 and prepared STFs. As seen from the graph, the viscosity values of the samples increased with increasing silica concentration. Furthermore, PEG 300 exhibits Newtonian fluid behavior with no sudden increment in the viscosity with shear rate. The addition of silica nanoparticles into the PEG resulted in the sudden increment of the viscosity and STFs exhibited shear thickening behavior. However, STF5 sample did not show remarkable viscosity increment with increasing shear rate due to the lower silica content in the fluid. It was also observed from the graph, the STFs were glassy at rest and yielded at low shear rates, known as shear thinning which is a desired feature for the body armor.

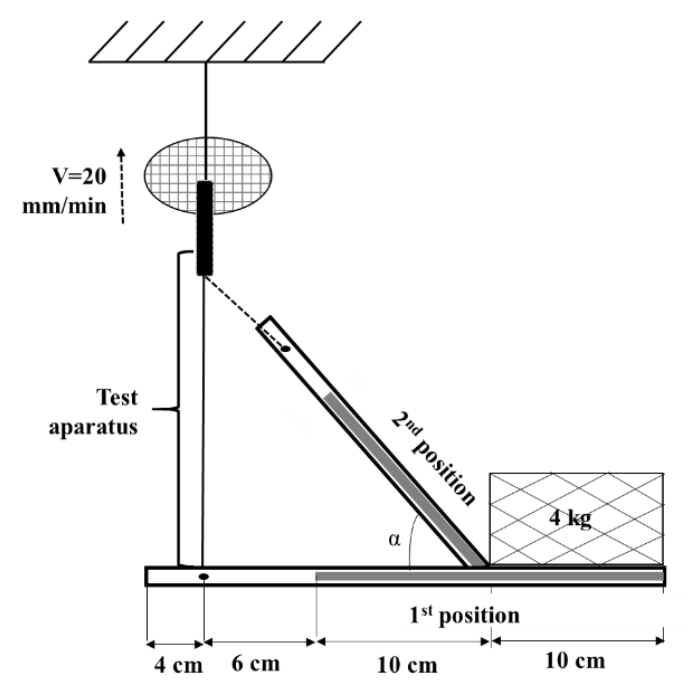

Figure 3. Schematic illustration of flexibility test setup

The viscosities of the STF20, STF25 and STF30 samples decreased with increasing shear rate up to $101 / \mathrm{s}$. The shear thinning stage of the samples appeared at similar shear rates. As increasing shear rate the viscosity begins to plateau, followed by a transition to shear thickening behavior at high shear rates. The sudden increase in the viscosity of silica dispersions and the shear thickening transitions are due to microstructural changes in the fluid along with the hydro cluster mechanism. The formation of particle clusters increases the hydrodynamic stress in the shear thickening fluid that leads to the dramatic increase in the viscosity [18, $26,27]$. The shear rate at which shear thickening behavior is observed is known as critical shear rate [28]. It was observed that the critical shear rate values decreased upon increment silica concentration in STFs. In addition, the strength of the shear thickening response increases as particle loading increases with continuous shear thickening behavior.

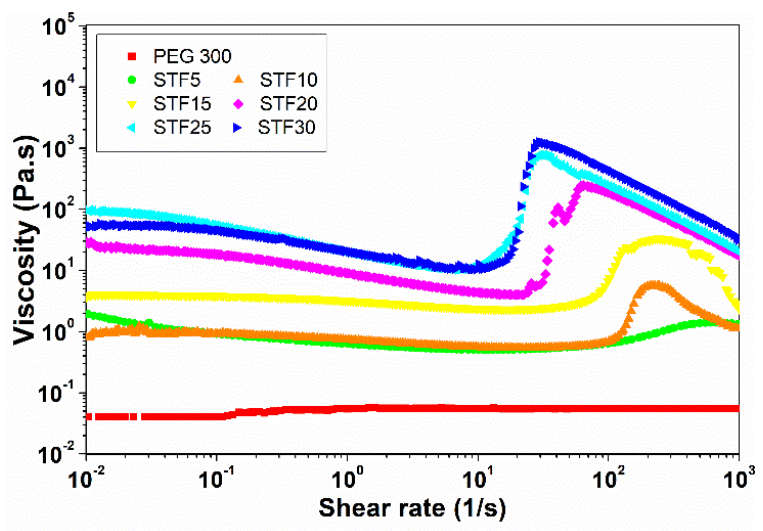

Figure 4. Steady shear viscosity-shear rate graph of PEG 300 and STFs

The range of shear rates at which shear thickening behavior is observed and the viscosity values at these ranges are given in Table 2 for all prepared STFs. The sample containing 30 
wt. \% silica exhibited the highest thickening effect with sudden and continuous increment in viscosity.

After shear thickening transition, the second shear thinning regime was visible at higher shear rates which is known as reversible shear thickening, and it is an important issue for multi shots of body armors.

Table 2. The range of shear rates and viscosity values of STFs

\begin{tabular}{ccc}
\hline Sample Code & $\begin{array}{c}\text { Range of shear rates } \\
\left(\mathrm{s}^{-1}\right)\end{array}$ & $\begin{array}{c}\text { Viscosity values } \\
(\text { Pa.s })\end{array}$ \\
\hline STF5 & - & - \\
STF10 & $5-129$ & $1.2-12.4$ \\
STF15 & $34-43$ & $6.9-204.2$ \\
STF20 & $39-44$ & $2.8-350$ \\
STF25 & $11-30$ & $12-773$ \\
STF30 & $20-42$ & $42-1241$ \\
\hline
\end{tabular}

\subsection{Morphological characterization}

The SEM images of STF30 and STF30/aramid fabric are shown in Figures 5a and 5b-d, respectively. As seen from the Figure 5a, silica nanoparticles were well coated with PEG in STF30. SEM images of STF30/aramid fabric show that STF was well impregnated over the entire surface of the aramid fabric. The uniform coating was seen better from the higher magnification image (Figure 5d).
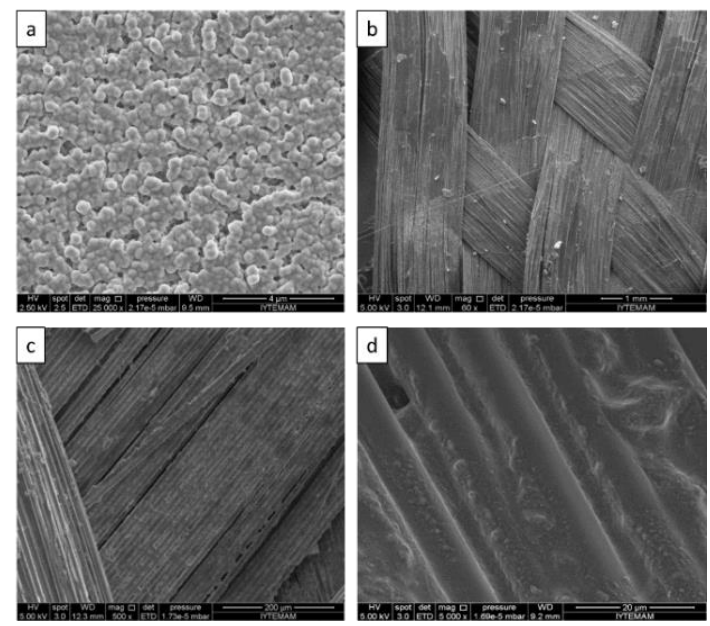

Figure 5. SEM images of (a) STF30 at 25000x magnifications and (b-d) STF30/aramid fabric at 60x, 500x and 2500x magnifications

\subsection{Quasi-static stab resistance}

The quasi-static stab resistance test results for the untreated aramid and STF/aramid fabrics are illustrated in Figure 6. As seen in the graph, all STF/aramid fabrics exhibited significantly higher penetration load as compared to those for the untreated aramid fabric targets. It was observed that STF30/aramid fabric exhibited the highest load of $127 \mathrm{~N}$ at about $30 \mathrm{~mm}$ penetration, whereas the aramid fabric gave $74 \mathrm{~N}$ at the same penetration depth. With increasing silica concentration shear thickening behavior was more obvious and stab resistance of this STF/aramid fabric enhanced.



Figure 6. Quasi-static stab resistances of aramid fabric and STF/aramid fabrics

\subsection{Dynamic stab resistance}

It is important to determine the stab resistance of the armors at higher velocities. Dynamic stab resistance test was performed to obtain the penetration depths of the samples. Penetration depth versus impact velocities graph for the aramid fabric and STF/aramid fabrics is illustrated in Figure 7. The three impact velocities used during the tests are marked on the graph. For all impact velocities, aramid fabric target exhibited the lowest stab resistance with the highest penetration depths. With increasing silica concentration, the resistance to the stab of targets improved. It was observed that targets containing STF30/aramid fabric exhibited the least penetration depth and the highest stab resistance. However, as expected, as the impact velocity increased, a penetration depth of all targets increased. Figure 8 shows the example images of aramid fabric and STF30/aramid fabric during and after dynamic stab test at a $2.21 \mathrm{~m} / \mathrm{s}$ spike impact velocity. It was clearly seen that untreated aramid fabrics had higher penetration depth as compared to those for STF/aramid systems.

\subsection{Ballistic performance}

The untreated aramid fabrics and STF30/aramid fabrics which had highest stab resistances were subjected to ballistic impact with $9 \mathrm{~mm}$ FMJ parabellum and $1.1 \mathrm{~g}$ FSP projectiles. The test results were given in Table 3. For the $9 \mathrm{~mm}$ parabellum test, the typical projectile velocity was measured as $454 \mathrm{~m} / \mathrm{sec}$. At this velocity, the aramid fabrics punctured whereas, STF30/aramid sample did not puncture and resisted with about $55 \mathrm{~mm}$ deformation on the fabrics. 


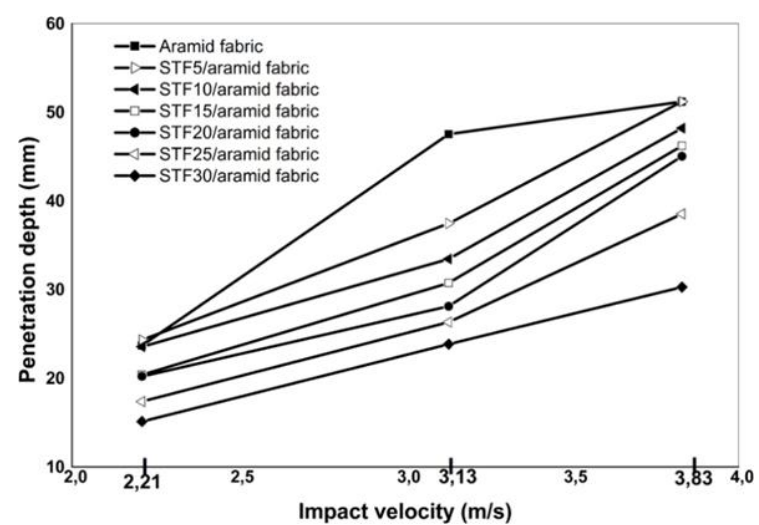

Figure 7. Dynamic stab resistances of aramid fabric and STF/aramid fabrics
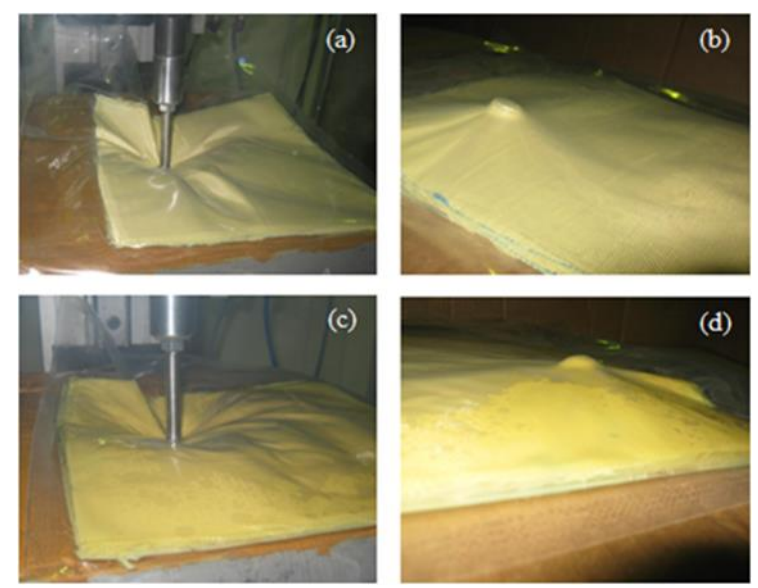

Figure 8. Images for aramid fabric (a) during, (b) after dynamic stab test and STF30/aramid fabric (c) during, (d) after dynamic stab test

In the $\mathrm{V}_{50}$ ballistic limit test in which $1.1 \mathrm{~g}$ FSPs are used, STF/aramid composites exhibited higher ballistic resistance as compared to those for the untreated fabrics. $\mathrm{V}_{50}$ ballistic test limits of aramid fabrics and STF30/aramid sample were measured as 504 and $530 \mathrm{~m} / \mathrm{sec}$, respectively. The results show that a relatively less damage, i.e., less penetration (no puncture or partial perforation) occurred within the fabrics impregnated with STFs. This may indicate a relatively higher energy absorbing capability of the composites with STF due to shear thickening effects and increased friction and stickiness.

Table 3. Ballistic test results of the samples

\begin{tabular}{ccc}
\hline Sample Code & $9 \mathrm{~mm}$ parabellum test result & $\begin{array}{c}\mathrm{V}_{50} \text { test result } \\
(\mathrm{m} / \mathrm{sec})\end{array}$ \\
\hline $\begin{array}{c}\text { Aramid fabric } \\
\text { STF30/aramid } \\
\text { fabric }\end{array}$ & $\begin{array}{c}\text { Punctured } \\
\text { mm deformation }\end{array}$ & 504 \\
\hline
\end{tabular}

\subsection{Flexibility test}

Body armors are bulky, heavy, hard to wear, restrictive the mobility of the wearer due to this laminated structure and heavy plates. There is always needed to develop soft body armor materials with flexible, lightweight, higher protection levels against ballistic threats. Flexibility is a critical feature for body armor not to restrict the mobility of the wearer. Therefore, the flexibility test was performed to determine the effect of STF addition on the fabric flexibility by using Shimadzu AGS-J universal test machine with a $5 \mathrm{kN}$ load cell. Based on our knowledge, the study reported by Lee et. all. [6] is the only one as the flexibility test for this purpose. They used two-dimensional drape tests with $20 \mathrm{~g}$ weight which was attached to the target ends and bending angle was reported as a measure of target flexibility, with larger angles indicating greater flexibility. However, this method depends on handicraft. It is inaccurate especially for lower bending angles and time-consuming. Therefore, in our study, a new rapid and simple to implement flexibility test setup was established by modifying the tensile test setup in Shimadzu AGS-J universal test machine based on the measurements of bending angle, which is a measure of target flexibility, with larger angles indicating greater flexibility. The flexibility test results for the aramid fabrics and STF impregnated aramid fabrics are presented in Table 4. No significant difference in flexibility between the aramid fabrics with and without impregnated STFs was observed. This indicates that the addition of STF causes a relatively small amount of change in the flexibility of aramid fabrics at low rates of deformation, as desired. Untreated aramid exhibited the highest flexibility with $24^{\circ}$ bending angle. Bending angles of STF/aramid targets were observed to decrease with increasing silica concentration in STF as compared to aramid fabric.

Table 4. The flexibility test results for the aramid fabric and STF/aramid fabrics

\begin{tabular}{ccc}
\hline Sample code & $\begin{array}{c}\text { Bending at } \\
\text { the edge of } \\
\text { the sample } \\
(\mathrm{mm})\end{array}$ & $\begin{array}{c}\text { Bending angle, } \\
\alpha\left(^{\circ}\right)\end{array}$ \\
\hline Aramid fabric & 45 & 24.23 \\
STF5/aramid & 43 & 23.26 \\
STF10/aramid & 41 & 22.29 \\
STF15/aramid & 40 & 21.8 \\
STF20/aramid & 38 & 20.8 \\
STF25/aramid & 37 & 20.3 \\
STF30/aramid & 36 & 19.8 \\
\hline
\end{tabular}

\section{Conclusion}

This study reported the steady-shear rheological properties of fumed silica based STFs at different weight fractions and the stab resistances of aramid fabrics impregnated with STFs. Steady-shear rheological experiments demonstrated that with the addition of silica 
nanoparticles into the PEG, shear thickening behavior was observed, and this response was more obvious at STFs with higher silica concentration. On the other hand, STF/aramid fabrics showed a significant enhancement in stab resistance as compared with untreated aramid. Both stab and rheological experiments show that increasing shear thickening response corresponds to increased stab performance in STF/aramid fabrics. Nevertheless, there was no significant difference between untreated aramid and STF/aramid targets in the matter of flexibility. As a conclusion, the impregnation of shear thickening fluids consisting $30 \%$ (w/v) of fumed silica onto the aramid fabrics resulted in the highest quasi-static and dynamic stab and ballistic resistances without negative effect on flexibility.

\section{Acknowledgments}

The authors gratefully acknowledge the support of BARIŞ Electrical Industry Inc. and Undersecretariat for Defence Industries of Turkey (SSM) for financial support.

\section{Conflict of interest}

The authors declare that there is no conflict of interest.

\section{Similarty rate: $\% 15$}

\section{References}

[1] B.A. Cheeseman, T. A. Bogetti, Ballistic impact into fabric and compliant composite laminates, Composite $\begin{array}{llll}\text { Structures, } & 61 & (1), & 161-173,\end{array}$ https://doi.org/10.1016/S0263-8223(03)00029-1.

[2] M. Decker, C. J. Halbach, C. H. Nam, N. J. Wagner, E. D. Wetzel, Stab resistance of shear thickening fluid (STF)-treated fabrics, Composites Science and Technology, $67 \quad$ (3), 565-578, 2007. https://doi.org/10.1016/j.compscitech.2006.08.007.

[3] H. M. Rao, M. Hosur, J. Mayo, S. Burton, S. Jeelani, Stab Characterization of Hybrid Ballistic Fabrics, Proceedings of the Annual Society for Experimental Mechanics Conference, pp. 1-4, Albuquerque, New Mexico, USA, 2009.

[4] V. B. C. Tan, T. E. Tay, and W. K. Teo, Strengthening fabric armour with silica colloidal suspensions, International Journal of Solids and Structures, 42 (5), 1561-1576, 2005. https://doi.org/10.1016/j.ijsolstr.20 04.08.013.

[5] A. Srivastava, A. Majumdar, and B. Butola, Improving the impact resistance of textile structures by using shear thickening fluids: a review, Critical Reviews in Solid State and Materials Sciences, 37 (2), 115-129. 2012. https://doi.org/10.1080/10408436.2011.613493.

[6] Y. S. Lee, E. D. Wetzel, and N. J. Wagner, The ballistic impact characteristics of Kevlar ${ }^{\circledR}$ woven fabrics impregnated with a colloidal shear thickening fluid, Journal of Materials Science, 38 (13), 2825-2833, 2003. https://doi.org/10.1023/A:1024424200221.

[7] Y. Duan, M. Keefe, T. A. Bogetti, B. Powers, Finite element modeling of transverse impact on a ballistic fabric, International Journal of Mechanical Sciences, 48 (1), 33-43, 2006. https://doi.org/10.1016/j.ijmecsci. 2005.09.007.
[8] A. Srivastava, A. Majumdar, and B. S. Butola, Improving the impact resistance performance of Kevlar fabrics using silica based shear thickening fluid, Materials Science and Engineering: A, 529, 224-229, 2011. https://doi.org/10.1016/j.msea.2011.09.021.

[9] H. Barnes, Shear-thickening ("Dilatancy") in suspensions of nonaggregating solid particles dispersed in Newtonian liquids, Journal of Rheology, 33 (2), 329366, 1989, https://doi.org/10.1122/1.550017.

[10] Y. S. Lee and N. J. Wagner, Dynamic properties of shear thickening colloidal suspensions, Rheologica Acta, 42 (3), 199-208, 2003. https://doi.org/10.1007 /s00397-002-0290-7.

[11] T. J. Kang, C. Y. Kim, and K. H. Hong, Rheological behavior of concentrated silica suspension and its application to soft armor, Journal of Applied Polymer Science, 124 (2), 1534-1541, 2012. https://doi.org/10.1 002/app.34843.

[12] E. D. Wetzel, Y. S. Lee, R. G. Egres, K. M. Kirkwood, J. E. Kirkwood, and N. J. Wagner, The effect of rheological parameters on the ballistic properties of shear thickening fluid (STF)-Kevlar composites. AIP Conference Proceedings, 712, 288-293, 2004. https://doi.org/10.1063/1.1766538.

[13] D. P. Kalman, J. B. Schein, J. M. Houghton, C. H. N. Laufer, E. D. Wetzel, and N. J. Wagner, Polymer dispersion based shear thickening fluid-fabrics for protective applications. Proceedings of SAMPE, pp. 19, Baltimore, 2007.

[14] N. Kagei, D. Kanie, and M. Kawaguchi, Viscous fingering in shear thickening silica suspensions. Physics of Fluids, 17 (5), 054103, 2005. https://doi.org/10.1063/1.1894407.

[15] T. A. Hassan, V. K. Rangari, and S. Jeelani, Sonochemical synthesis and rheological properties of shear thickening silica dispersions, Ultrasonics $\begin{array}{llll}\text { sonochemistry, } 17 \quad(5), \quad 947-952, & 2010 .\end{array}$ https://doi.org/10.1016/j.ultsonch.2010.02.001.

[16] J. R. Melrose and R. C. Ball, "Contact networks" in continuously shear thickening colloids, Journal of Rheology, $48 \quad$ (5), 961-978, 2004. https://doi.org/10.1122/1.1784784.

[17] R. Hoffman, Discontinuous and dilatant viscosity behavior in concentrated suspensions. I. Observation of a flow instability, Transactions of The Society of Rheology, $16 \quad$ (1), 155-173, 1972. https://doi.org/10.1122/1.549250.

[18] W. H. Boersma, J. Laven, and H. N. Stein, Shear thickening (dilatancy) in concentrated dispersions. AIChE Journal, 36 (3), 321-332, 1990. https://doi.org/10.1002/aic.690360302.

[19] N. J. Wagner and J. F. Brady, Shear thickening in colloidal dispersions, Physics Today, 62 (10), 27-32, 2009. https://doi.org/10.1063/1.3248476.

[20] R. P. Chhabra and J. F. Richardson, Non-Newtonian Flow and Applied Rheology: Engineering Applications, Butterworth-Heinemann. 2011.

[21] M. J. Decker, C. J. Halbach, C. H. Nam, N. J. Wagner, and E. D. Wetzel, Stab resistance of shear thickening 
fluid (STF)-treated fabrics, Composites Science and Technology, 67 (3), 565-578, 2007. https://doi.org/ 10.1016/j.compscitech.2006.08.007.

[22] W. Li, D. Xiong, X. Zhao, L. Sun, and J. Liu, Dynamic stab resistance of ultra-high molecular weight polyethylene fabric impregnated with shear thickening fluid. Materials \& Design, 102, 162-167, 2016. https://doi.org/10.1016/j.matdes.2016.04.006.

[23] X. Feng, S. Li, Y. Wang, Y. Wang, and J. Liu, Effects of different silica particles on quasi-static stab resistant properties of fabrics impregnated with shear thickening fluids. Materials \& Design, 64, 456-461, 2014. https://doi.org/10.1016/j.matdes.2014.06.060.

[24] D. P. Kalman, R. L. Merrill, N. J. Wagner, and E. D. Wetzel, Effect of particle hardness on the penetration behavior of fabrics intercalated with dry particles and concentrated particle- fluid suspensions, ACS Applied
Materials \& Interfaces, 1 (11), 2602-2612, 2009. https://doi.org/10.1021/am900516w.

[25] Standard, N., 0115.00, Stab Resistance of Personal Body Armor. US Department of Justice, Office of Justice Programs, National Institute of Justice, 2000.

[26] G. Bossis and J. F. Brady, The rheology of Brownian suspensions. The Journal of Chemical Physics, 91 (3), 1866-1874, 1989. https://doi.org/10.1063/1.457091.

[27] J. Bender and N. J. Wagner, Reversible shear thickening in monodisperse and bidisperse colloidal dispersions, Journal of Rheology, 40 (5), 899-916, 1996. https://doi.org/10.1122/1.550767.

[28] M. Chellamuthu, E. M. Arndt, and J. P. Rothstein, Extensional rheology of shear-thickening nanoparticle suspensions, Soft Matter, 5 (10), 2117-2124, 2009. https://doi.org/10.1039/B820684H. 